\title{
M-BACOS Regimen
}

National Cancer Institute

\section{Source}

National Cancer Institute. M-BACOS Regimen. NCI Thesaurus. Code C9886.

A chemotherapy regimen consisting of methotrexate, leucovorin, doxorubicin, vincristine, bleomycin, cyclophosphamide and methylprednisolone that may be used in the treatment of non-Hodgkin lymphoma (NHL). 